pÿPicturing voice: Visual Methods and Children s Voices in Finnish Education

Kumpulainen, Kristiina

2016-11

pÿKumpulainen , K 2016 , ' Picturing voice: Visual Methods and Children s Voices in Finnish

Education ' , IMAG , vol. 1 , no. 3 , pp. 210-212 . < http://insea.org/publications/imag >

http://hdl.handle.net/10138/232904

cc_by_sa

publishedVersion

Downloaded from Helda, University of Helsinki institutional repository.

This is an electronic reprint of the original article.

This reprint may differ from the original in pagination and typographic detail.

Please cite the original version. 


\section{Picturing Voice: Visual Methods and Children's Voices in Finnish Education}

Kristina Kumpulainen

University of Helsinki 


\section{Introduction}

\section{Picturing Voice: Visual Methods and Children's Voices in Finnish Education}

\begin{abstract}
In this paper, I will discuss how children's use of visual methods provides possibilities for researchers and educators to understand children's voices. Drawing on sociocultural and dialogic approaches, my conclusion challenges simplistic notions of gaining access to and understanding children's voices. On the contrary, as my empirical examples show, the visually mediated voices of children should be understood as interactional achievements shaped by their cultural, social, and material contexts. As such, visual methods appear to offer children rich means of expression, which can result in new meanings, emotions, and experiences for everyone involved.
\end{abstract}

Keywords: children's voice, visual methods, sociocultural and dialogic approaches, visual ethnography, education
In Finnish education, there has been increased interest in acknowledging children's voices in the educational process. The underlying rationale for this interest is manifold. From one perspective, it stems from initiatives that stress children's visibility and position in society and entail respecting their right to express opinions and have a say in matters that affect their lives (The United Nations Convention on the Rights of the Child, 1989). Another explanation holds that listening to children's voices, that is, their meanings, experiences, opinions, and perspectives in relation to their life worlds, creates avenues for educators to learn about children and, hence, to support their holistic learning and well-being. It has been suggested that weaving children's voices into the educational process promotes educational equity and opportunity (Kumpulainen, Lipponen, Hilppö, \& Mikkola, 2013).

Visual methods, such as the creation of drawings, photographs and videos have gained popularity among Finnish educators and researchers as potential means to gain access to children's voice in their life worlds. Visual methods are regarded as natural, child-sensitive means that communicate children's voices in multiple, authentic ways in their full complexity and that pass on knowledge about the world as experienced by children: knowledge that would be difficult, if even impossible, to gain in other ways (Clark, 2005). Visual methods are also linked to other creative and aesthetic forms of self-expression, 
holding emancipatory power that helps the narrator find her voice and identity (Bragg, 2011; Brushwood Rose \& Low, 2014). Lorenz (2010) defines visual artifacts as metaphors that bring alive emotions and personal experiences and help children share and reflect upon their sense-making. Overall, the meaning of visual methods for education is thought to be important in a world that is based largely on pre-described performance and accountability in which there is little room for emotions, creativity, and personal interpretation (Kumpulainen, Mikkola, \& Salmi, 2015).

In this paper, drawing on my own empirical research, I discuss how children's use of visual methods, including drawing and photography, provides possibilities for researchers and educators to reach and hear children's voices. My work is guided by the following questions.

- What can we learn from children's visually-mediated voices in their life worlds?

- How are children's voices constructed into being in children's visual narratives?

\section{Sociocultural and dialogic approach to children's voices}

The theoretical framework of my research for conceptualizing children's voices as culturally embedded and tool-mediated is based on sociocultural and dialogic notions (Bakhtin, 1981; Vygotsky, 1978; Wertsch, 1991). Vygotsky (1978) explains the mediating role of tools in human interaction using the concept of double stimulation, in which an external tool is employed or created for intentional, voluntary problem-solving activities. In other words, to redefine situations and control their own actions, people develop and use artifacts in order to transform the contexts in which they act (Virkkunen, 2006).

My thinking has also been guided by visual ethnography, which invites children to explore and document their experiences and perspectives through a process of visual narrative inquiry (Bach, 2008; Pink, 2007). From this perspective, voice is not an objective, mental quality or state of mind but rather is constructed into being in interactions between the individual and the collective and sociomaterial environment. Voices are mediated by the values and rules of the community, by participating individuals, and by the material and conceptual resources available.

\section{Researching children's voices: Background to empirical research}

Together with my co-researchers, I am interested in investigating young children's use of visual methods to document and share positive events in their lives, both at school and outside of school. By positive events, I mean moments or experiences that are meaningful and important to children's everyday lives from their own perspectives. I have conducted visual research with children aged 3 to 12 in Finnish 
early childhood centers, primary schools, and in the children's homes and communities. I paid careful attention to research ethics to respect and honor the integrity of the children and their communities (Sime, 2008).

After making sure the children feel comfortable and confident using visual methods, their activities are anchored in the topic under investigation. For young children, the orienting activities often draw on children's literature and/or peer culture to address abstract topics, including happiness and joy. Next, children draw or take photographs of experiences in their lives. After this visual documenting, children take part in group discussions with their peers, teachers and/or other adults to view, share, and reflect upon their visual artifacts. The children decide which pictures to talk about and for how long (Cook \& Hess, 2007). These group sessions are video-recorded for further analysis. The research discussed below draws on empirical data from one preschool classroom community in Finland with children aged five to seven years old.

\section{Lessons learned: Children's visually mediated voices of their life words}

Our research demonstrates the multiplicity of children's voices mediated by using visual methods. From our research, we have learned that children attribute their positive experiences to relationships with important others, the use of various artifacts in their social practices, and everyday activities and accomplishments. Children's visual narratives have not entailed extraordinary or extreme experiences, but rather, just the opposite. In many cases, they have been small but important moments as demonstrated by the children's photo images (see Figures 1, 2, and 3). In accordance with earlier research, we can conclude that the positive events in children's lives may be so small that they go unnoticed if one does not deliberately focus on identifying them (Kumpulainen, et al., 2013). 


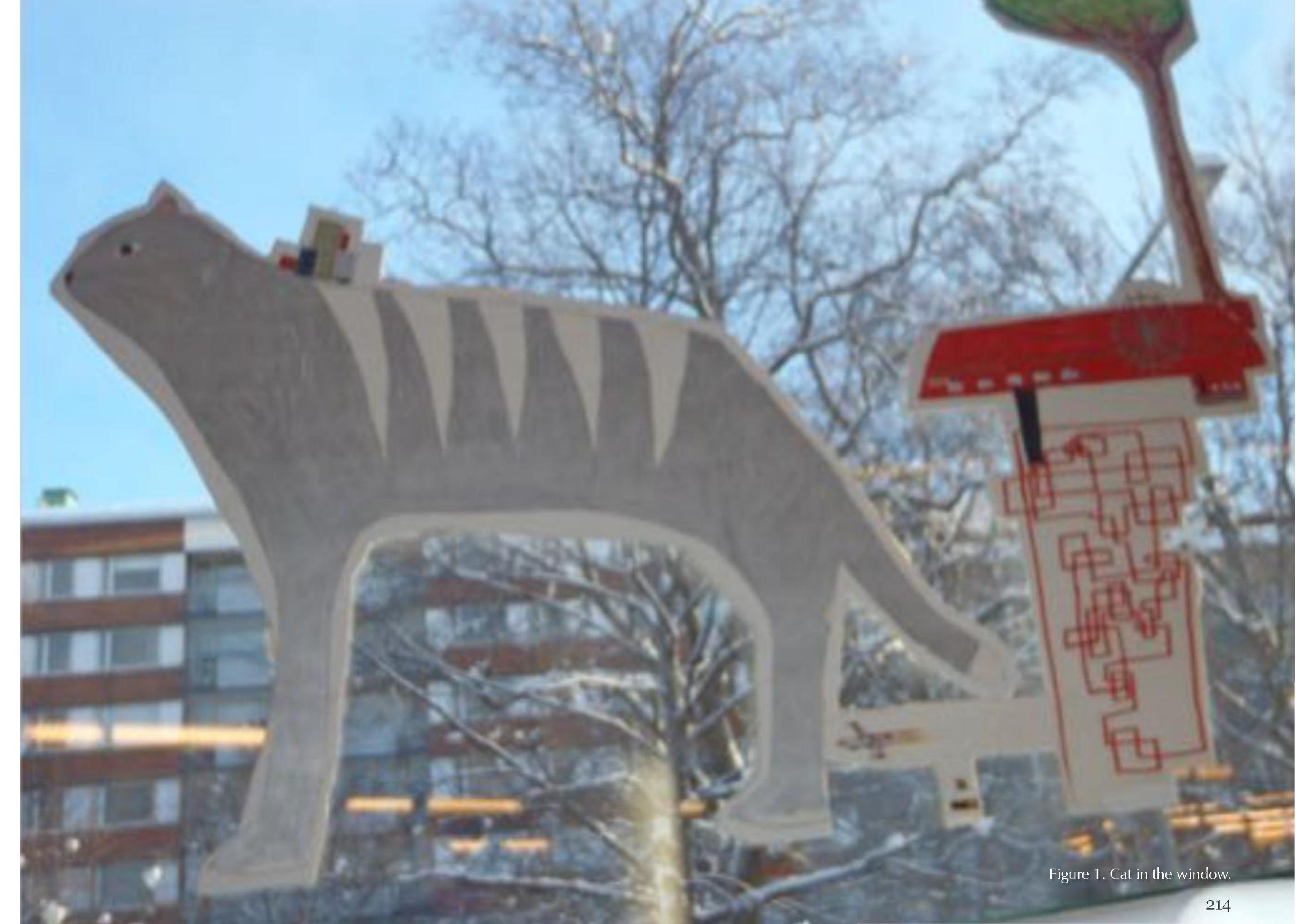




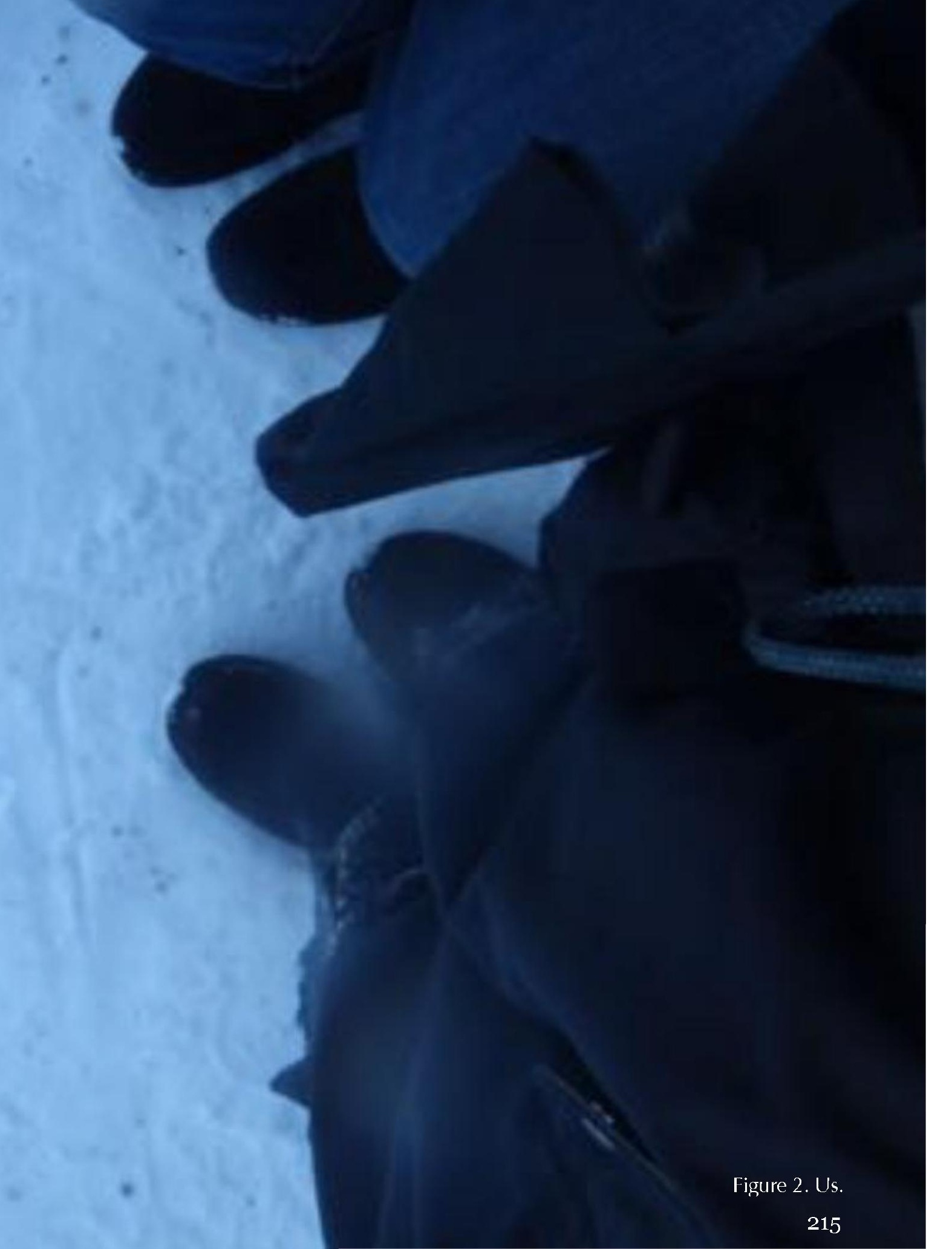




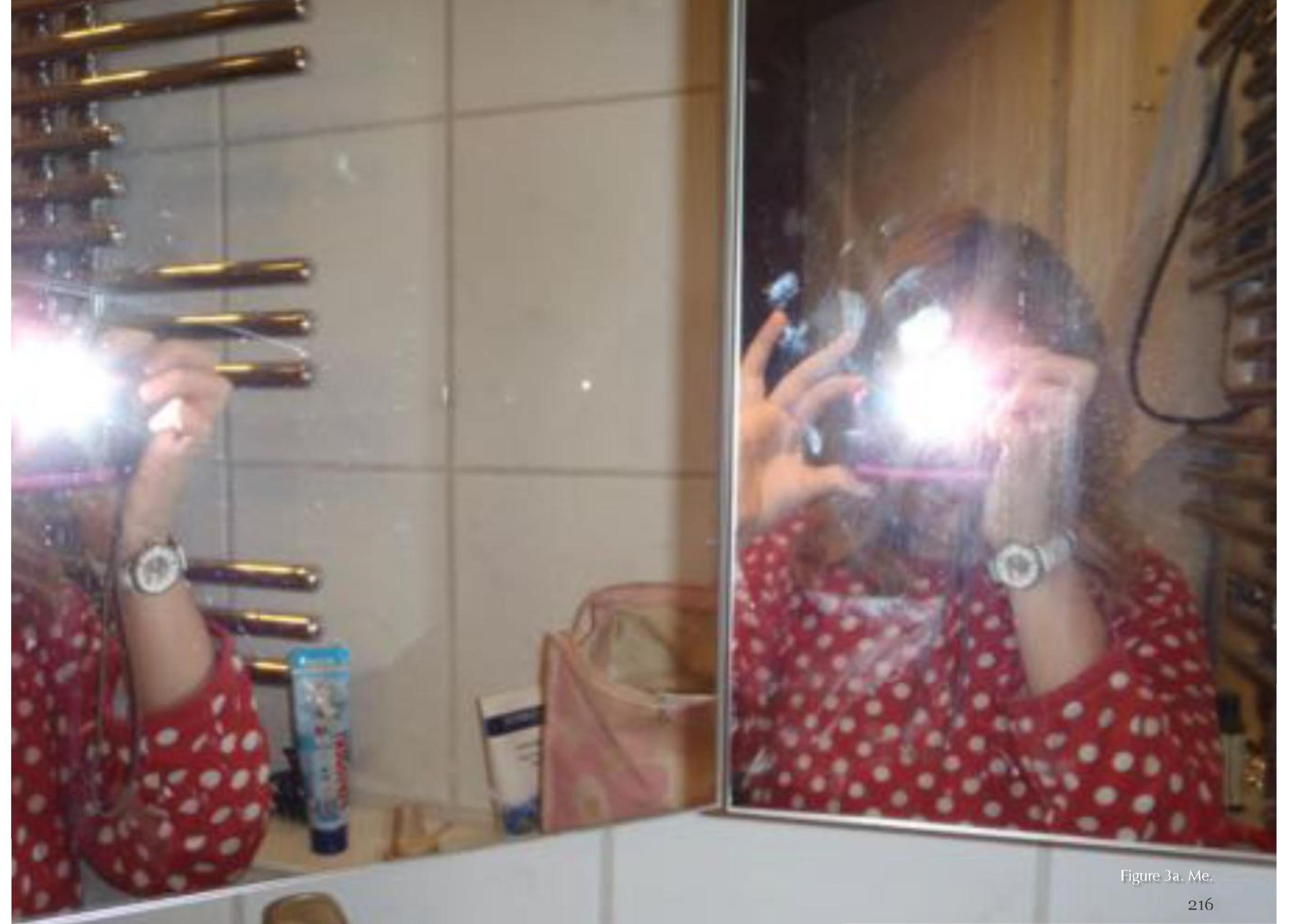




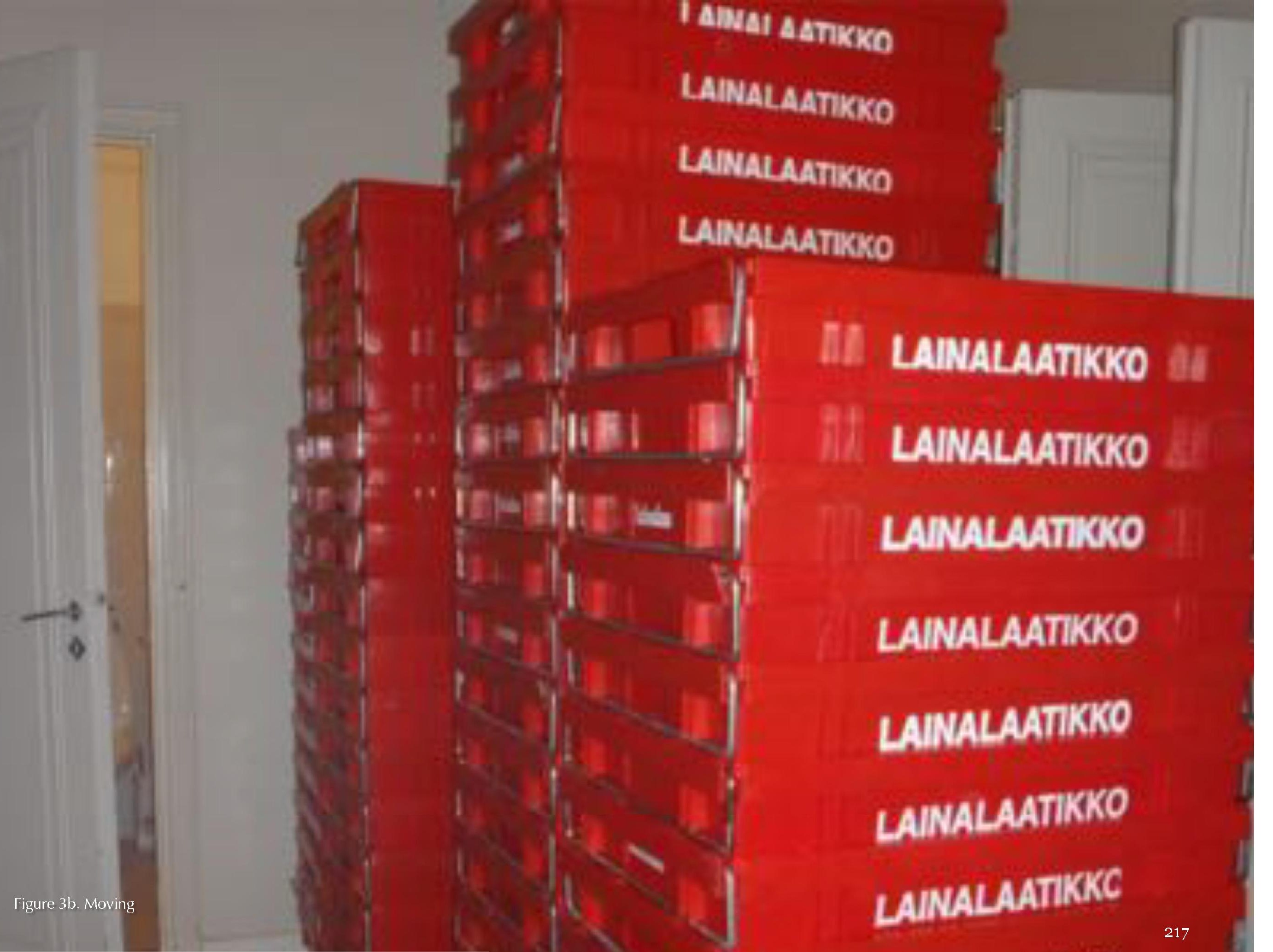


At the same time, our research has pointed out the complexity that visual methods entail in revealing children's voices. For example, visual tools, including cameras, have played a pivotal part in children's documenting and its outcomes. For some children, cameras have been more than just documentation tools; cameras have become part of their play activities and experiences. As our findings imply, children's visually mediated voices are very much about creative problem-solving rather than static, simplistic communication of fixed meanings and understandings.

In the example below, Anna explains that she wants to capture the beautiful spring weather, because it is an important source of her happiness and positive emotions (Figure 4). According to Anna, it has not been an easy task, and she explains how she has engaged in creative problemsolving to document this abstract experience.

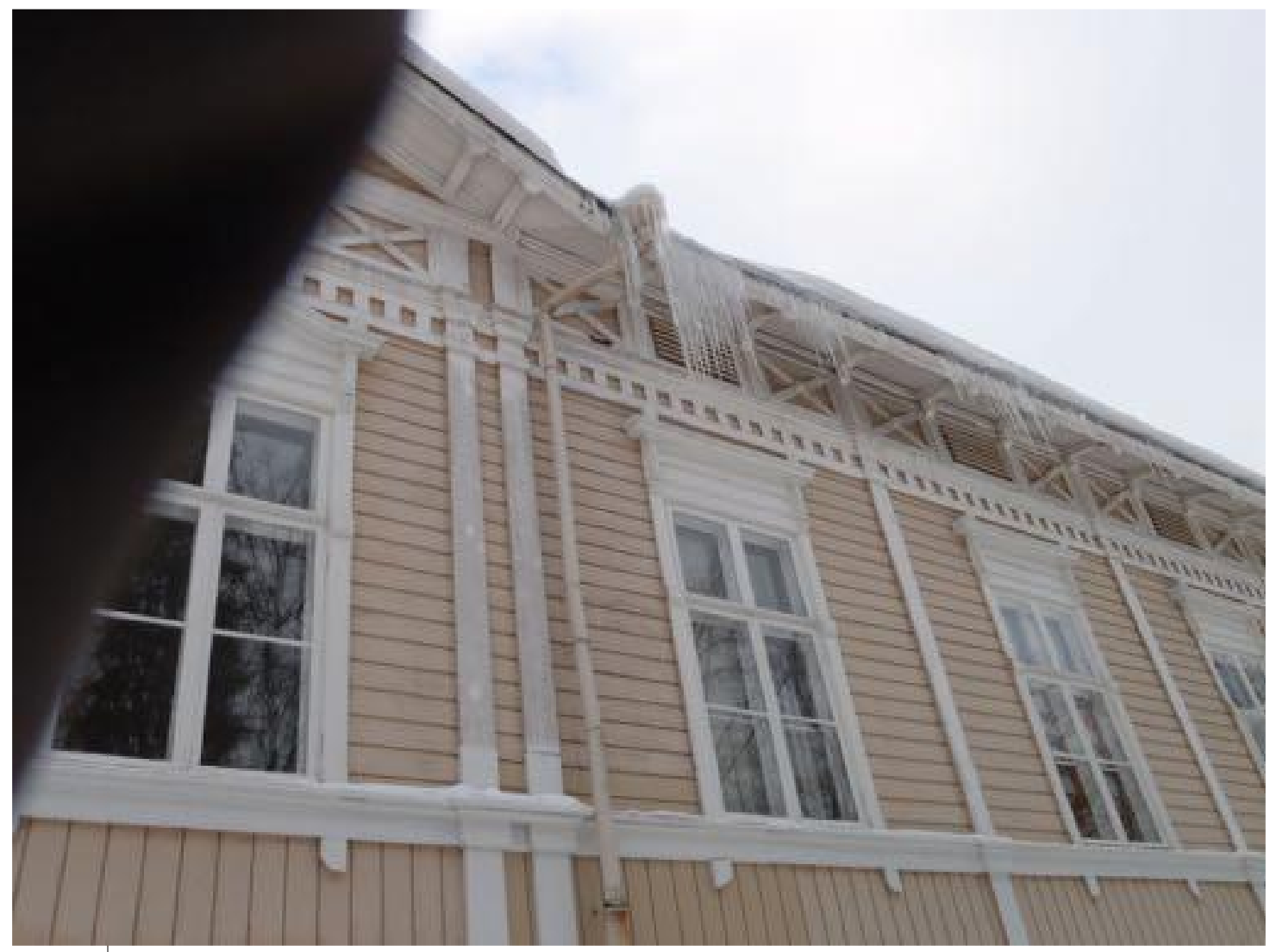

Figure 4. Spring weather.

Adult: Why did you want to take this picture?

Anna: Since weather feels so superfun and kind of playful.... And since weather is difficult to picture since it is invisible, I decided to take a picture of those huge ice....

Adult: Ice cycles.

Adult: Aaaahhh.

Adult: Now, when you say this, we can also see the weather, even though it is invisible.

Anna: It looks like there is... (incomplete sentence, left with wonder) 
The next example shows how positive emotions are also built during joint engagement with the photos. Here, Michael has taken a picture of his friends playing and running on the playground of their preschool (Figure 5). The reflections from children's clothing make them look like they are running like the wind.

At times, visual documentation in itself has turned into a vehicle for children's agency and has created new, positive experiences for the children (Brushwood Roe \& Low 2014). In the next example, Pete is sharing his picture from his trip to the library, where he observed beautiful, colorful dolls (Figure 6). He wants to share and discuss the photo, in which he managed to get movement into the picture. This example demonstrates how the child built an esthetic, creative relationship between himself and the dolls that accounted for his positive experience. Here, the child's engagement in planning, experimenting, and plying with the camera contribute to the creation of

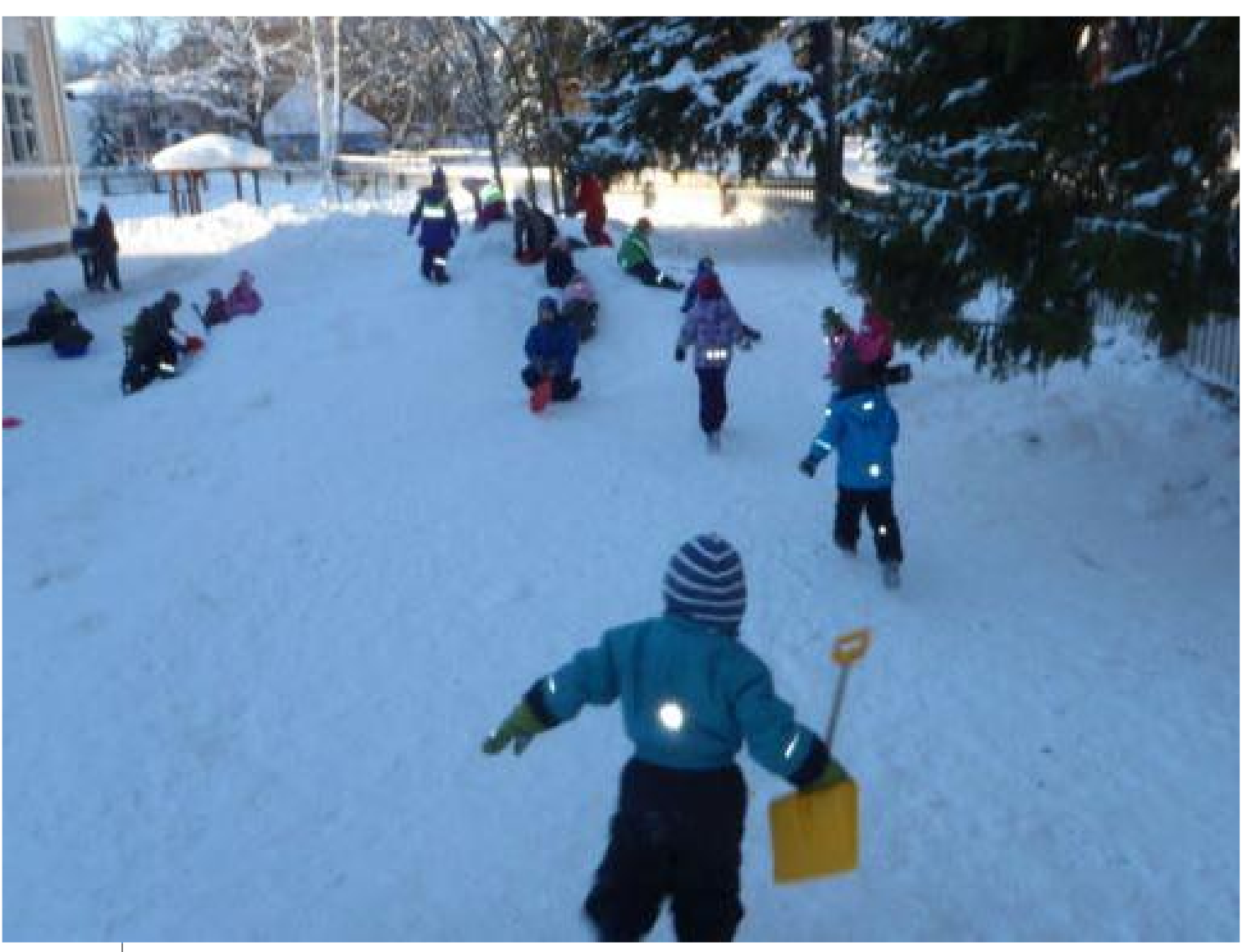
the picture and the positive experience.

Figure 5. Running like the wind.

Michael: This is the best (refers to his photo). Look how those reflections, look, look as if Jude is running like the speed of light... (anxious and eager voice). 


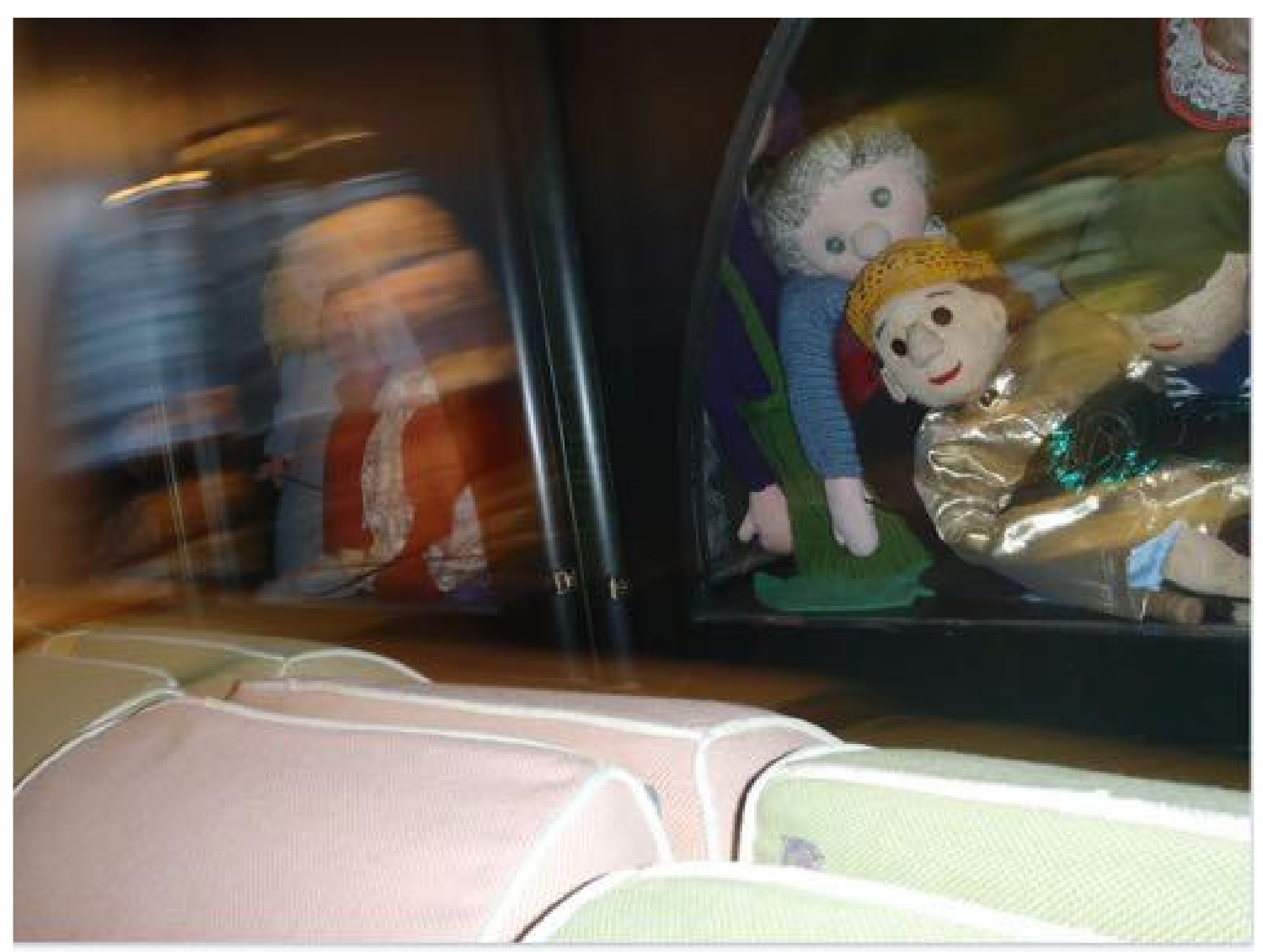

\section{Conclusion}

In visual research, researchers are doomed to struggle amid critical realism, which attempts to capture experience via visual means, although understanding of experience can never be objectively obtained (Luttrell \& Chalfen, 2010). Buckingham (2009) also warns researchers of naïve empiricism that holds that visual methods allow capturing individuals' voices in simple, authentic ways. It thus important to recognise that visual research with children requires interpretation, which is always an interactional achievement

These arguments are confirmed by our research on children's visual narration of their voices in their life worlds. Our findings challenge simplistic notions of gaining access to and understanding children's voices. Visual methods entail not only the artifact, but the story

Figure 6 . Doll on the move. behind the artifact and the creative processes mediated

Michael: Why does it move? It's difficult to make sense of it.

Pete: Yes, you can; it looks like it is moving around.

Adult: Mmmm.

Adult: Yeah you're right. It looks like...

Pete: And there are many colors. 
by cultural, social, and material contexts. Here, children' $\mathrm{s}$ visual documentation and narration illuminate the aesthetic, creative dimensions of children' $s$ voices situated in sociocultural contexts.

In sum, visual methods offer children rich means of expression, which, again, can result in new meanings, emotions, and experiences for everyone involved. By doing this, visual methods can create powerful contexts for education that acknowledge children's voices as multiple and multilayered stories for which the meanings are continuously evolving.

\section{Acknowledgements}

This research has been financially supported by the Academy of Finland (projects no. 135138 and 271362).

\section{REFERENCES}

- Bach, H. (2008). Visual narrative inquiry. In L. Given (Ed.), The SACE encyclopedia of qualitative research methods (pp. 939-941). Thousand Oaks, CA: SAGE Publications, Inc. doi: 10.4135/9781412963909.n490

- Bakhtin, M. (1986). Speech Genres and Other Late Essays. Austin: University of Texas Press.

- Bragg, S. (2011). "Now it's up to us to interpret it": "Youth voice" and visual methods in creative learning and research. In P. Thomson, \& J. Sefton-Green (Eds.) Researching Creative Learning; methods and approaches (pp. 88-103). London and NY: Routledge,

- Brushwood Rose, C., \& Low, B. (2013). Exploring the 'createdness' of multimedia narratives: from creation to interpretation. Visual Studies 29(1), 30-39.

- Buckingham, D. (2009). Creative visual methods in media research: Possibilities, problems and proposals. Media, Culture and Society 31(4),633-652.

- Clark, A. (2005). Listening to and involving young children: a review of research and practice. Early Childhood Development and Care, 175(6), 489-505.

- Cook, T., \& Hess, E. (2007). What the camera sees and from whose perspective. Fun methodologies for engaging children 
in enlightening adults. Childhood, 14(1), 29-45. doi: $10.1177 / 0907568207068562$

- Kumpulainen, K., Lipponen, L., Hilppö, J., \& Mikkola, A. (2013). Building on the positive in children's lives: a coparticipatory study on the social construction of children's sense of agency. Early Child Development and Care, 1-19. doi: 10.1080/03004430.2013.778253

- Kumpulainen, K., Mikkola, A., \& Salmi, A. (2015). Osallistava visuaalinen tutkimus ja lapsen äänen tavoittaminen. In $M$. Böök, Mustola, M., A-V. Kärnä, \& J. Mykkänen (Eds.), Visuaaliset menetelmät lapsuuden- ja nuorisotutkimuksessa (pp. 136-144). Helsinki: Nuorisotutkimusseura/ Nuorisotutkimusverkosto.

- Lorenz, L. (2010). Visual metaphors of living with brain injury: Exploring and communicating lived experience with an invisible injury. Visual Studies. 25(3), 210-223.

- Luttrell, W., \& Chalfen, R. (2010). Lifting up voices of participatory visual research. Visual Studies 25(3), 197-200.

- Pink, S. (2007). Doing visual ethnography. London: Sage Publications Ltd.

- Sime, D. (2008). 'Ethical and methodological issues in engaging young people living in poverty with participatory research methods'. Children's Geographies 6(1), 63-78.
- The United Nations Convention on the Rights of the Child (1 1989 ). Retrieved from http://www.unicef.fi/files/unicef/pdf/LOS A5fi.pdf

- Virkkunen, J. (2006). Dilemmas in building shared transformative agency. Activite's, 3(1), 19-42.

- Vygotsky, L.S. (1978). Mind in society: The development of higher mental processes. Cambridge, MA: Harvard University Press.

- Wertsch, J. (1991). Voices of the Mind: A Sociocultural Approach to Mediated Action. Cambridge, MA: Harvard University Press. 